\title{
REALISTA Y SENTIMENTAL: LA EXPERIENCIA DE LA COTIDIANIDAD Y SU RELACIÓN CON LA POLIS
}

Claude LE BIGOT

Université Rennes 2 / CELLAM

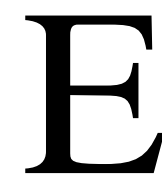

ntre los cambios que se produjeron en el panorama poético de los últimos treinta años, una nómina bastante larga de poetas manifestaron su interés por la cotidianidad y nuestro modo de vida en el marco urbano. «Nunca la poesía española ha sido tan urbana como ahora», escribía Miguel García-Posada (1996: 16) y añadía que el fenómeno se extendía mucho más allá de los "poetas de la experiencia". Este predominio de temas y motivos urbanos viene acompañado por una escritura de marcado carácter realista y pretende ahondar en lo que podemos llamar la cotidianidad como vector de las tensiones entre individuo y colectividad. No obstante, cabe recordar que entre lo infra-ordinario que anula la existencia, ya que en él nada sucede, y lo extraordinario que deja asombrado, lo cotidiano es una fuerza de adaptación permanente que estabiliza el aspecto vulnerable de la vida humana. Pero hay que reconocer que su configuración sufre el acondicionamiento de estructuras sociales duraderas como las instituciones, las reglas jurídicas, los sistemas de representaciones simbólicas y de valores sociales. La bipolaridad individuo/sociedad afecta los comportamientos y modos de pensar de maneras dispares según la sensibilidad y el ideario propio de los individuos. De modo que la cotidianidad encamina hacia posturas que pueden entrar en litigio con las normas dominantes. En una época de crisis, de incertidumbres y de disfuncionamientos, el poder uniformizador y modelizante de las tipificaciones sociales da lugar a cuestionamientos y revisiones a veces drásticos. Las ideologías políticas propusieron sus respuestas $\mathrm{y}$, como no dieron los resultados esperados, escritores y artistas, en particular, se asomaron mediante sus calas en la historia de lo humano a una "física" de las formas de experiencia de la cotidianidad en los que se experimentan sensaciones de placer o dolor, sentimientos de aflicción o de euforia, estados de frustración o de satisfacción inmediata. Que los poetas de la experiencia hayan visto en 
la observación de la cotidianidad un principio estructurante de su discurso, no puede sorprender, y aclara al mismo tiempo una vuelta al realismo que Luis Antonio de Villena había apuntado en el prólogo de su antología Fin de siglo al señalar lo siguiente:

\footnotetext{
[...] el giro hacia una intensificación del realismo y el coloquialismo, lo que llamo nueva poesía social (que desde luego no debe implicar descuido formal) acaso una poesía del realismo sucio (los aspectos más degradados o sórdidos de la vida urbana) o una poesía de mirada más colectiva. $\mathrm{O}$ desde otra perspectiva una indagación en la plural e inquietante condición psíquica del hombre, que abra nuevos caminos a la expresión razonada, brillante, comunicable -de la interioridad (Villena, 1992: 33; cursivas en el texto original).
}

Para el poeta que sondea la vía de acceso a lo real, la atención a lo cotidiano permite conciliar a un tiempo una aproximación realista y sentimental. Mirándolas de cerca, ciertas prácticas de la poesía realista que parecen pegarse a lo real al focalizarse en el detalle (una fotografía, un cartel publicitario, un diario abandonado en los pasillos del metro) acaban por des-naturalizar o des-construir lo real. Así, la lectura que se podrá hacer de la cotidianidad es ante todo considerarla como una producción en la economía general del sistema capitalista, en el que la producción genera el consumo, y en el que el consumo está dirigido y pedido no por aquellos que producen sino por los decidores (gestores y accionistas de los medios de producción).

Sin embargo en la medida en que la escritura realista tiende a dislocar una realidad hipertrofiada, no renuncia a mantener un discurso reflexivo sobre «la verdad inmediata de las emociones», como lo piensa Milan Kundera. La llamada actitud realista, cuando se focaliza en los aspectos disfóricos o eufóricos de lo cotidiano (éstos también existen) en su vertiente urbana orienta el espacio del lenguaje hacia una reflexión sentimental. Intentaremos aclarar esta aproximación a la cotidianidad examinando los dos puntos que quisimos sintetizar en el título de este trabajo con los calificativos de "realista y sentimental" para definir la experiencia y la poética de la cotidianidad.

\section{La experiencia de lo cotidiano: García Montero y Beltrán}

En el centro mismo de la problemática sobre la cotidianidad anida un debate teórico fundamental que Luis García Montero puso en el orden del día mediante lo que podríamos interpretar como un manifiesto, La otra sentimentalidad (1983). En él, el autor recuerda la imposibilidad de que la escritura se sustraiga de condicionamientos ideológicos, y también que las categorías kantianas de subjetividad y objetividad, de sensibilidad y razón han llevado a un esquematismo que aisló la poesía en un discurso noble, sublime y placentero. Pero al asignar a la poesía una vocación de superación de lo real y expresar un ideal de pureza, tal posicionamiento ignoraba el anclaje social e ideológico del poeta y se negaba a considerar que el lenguaje -fuente de cualquier 


\section{Tropelías. Revista de Teoría de la Literatura y Literatura Comparada, 18 (2012) Realista y sentimental: la experiencia de la cotidianidad y su relación con la polis} 59

práctica poética, en el sentido más amplio de la palabra- es históricamente condicionado. Para superar el esquematismo que opone razón y sensibilidad, pureza e impureza, L. García Montero propuso, partiendo de «la otra sentimentalidad» (expresión procedente del Juan de Mairena de Antonio Machado), historicizar la subjetividad, superando con ello la diferenciación entre esfera privada y esfera pública:

Cuando la poesía olvida el fantasma de los sentimientos propios se convierte en un instrumento objetivo para analizarlos (quiero decir, para conocerlos). Entonces es posible romper con los afectos, volver sobre los lugares sagrados como si fueran simples escenarios, utilizar sus símbolos hasta convertirlos en metáforas de nuestra historia. Pero no simplemente eso. Romper la identificación con la sensibilidad que hemos heredado significa también participar en el intento de construir una sentimentalidad distinta, libre de prejuicios, exterior a la disciplina burguesa de la vida (García Montero, 1993 : 186-187).

Cuando esta nueva concepción de la sentimentalidad se abrió camino en España, fueron muchos los autores que estimaron imprescindible fijar una mirada nueva sobre el mundo y necesaria la emergencia de una escritura nueva, devolviéndole a ésta toda la potencia de su materialidad, de donde surgió la referencia cada vez más frecuente en el discurso crítico sobre esta poética a «la escritura del cuerpo» (Rodríguez, 1999: 43-48); en realidad, otra manera de superar la dicotomía materia/espíritu en perspectiva resueltamente materialista. Ahora bien, el materialismo es inseparable de las manifestaciones concretas de las actividades del espíritu ${ }^{1}$. La filiación que establece Juan Carlos Rodríguez entre nueva sensibilidad y materialismo está objetivizada en el contexto del modo de producción capitalista (que considera la cultura como un producto, entre otros), pero lo relevante es que esa filiación evita las trampas en las que había caído el realismo social de los años 50. Una observación atenta de las realidades que abarca la "nueva sentimentalidad" llevó a Juan Carlos Rodríguez a postular la presencia de lo cotidiano en la poesía no como una temática sino como una práctica: «la práctica poética no [puede] partir de la conceptualización teórica de lo invisible capitalista, sino de los efectos concretos y experienciales de la vivencia de cada día» (Rodríguez, 1999: 46).

Si la poesía social tuvo tendencia a ignorar la parte de subjetividad ligada a la percepción de los mecanismos alienantes inherentes a la sociedad capitalista, "la otra sentimentalidad”, tal como la definió García Montero, llega a rehabilitar la expresión de la intimidad enfrentándose con la cotidianidad, ya que es precisamente a partir de esta relación entre el Yo y la sociedad como se opera la historicización de la subjetividad. Hoy en día, pese a los cambios indiscutibles, las relaciones entre los individuos siguen colocadas bajo el imperio de la violencia del modo de producción capitalista, ya se trate

\footnotetext{
${ }^{1}$ Recordemos con Jean Whal, si fuera necesario, que lo "concreto" no es la cosa, sino el contacto del espíritu y la cosa; en una palabra, la experiencia.
} 
de las relaciones jerárquicas en el mundo laboral, del poder de decisión en la empresa, de la segregación urbana, de la violencia sexista, todo aquello gobierna en una especie de lucha por la vida las relaciones sociales. Luis García Montero deja una visión exacta de la alteración, al deconstruir la armonía natural que mantenían las concepciones idealistas de la poesía. Esta es la lectura metapoética que se puede hacer del pastiche de la égloga garcilasiana que le permite representar individuos luchando con la masificación y la pérdida de identidad:

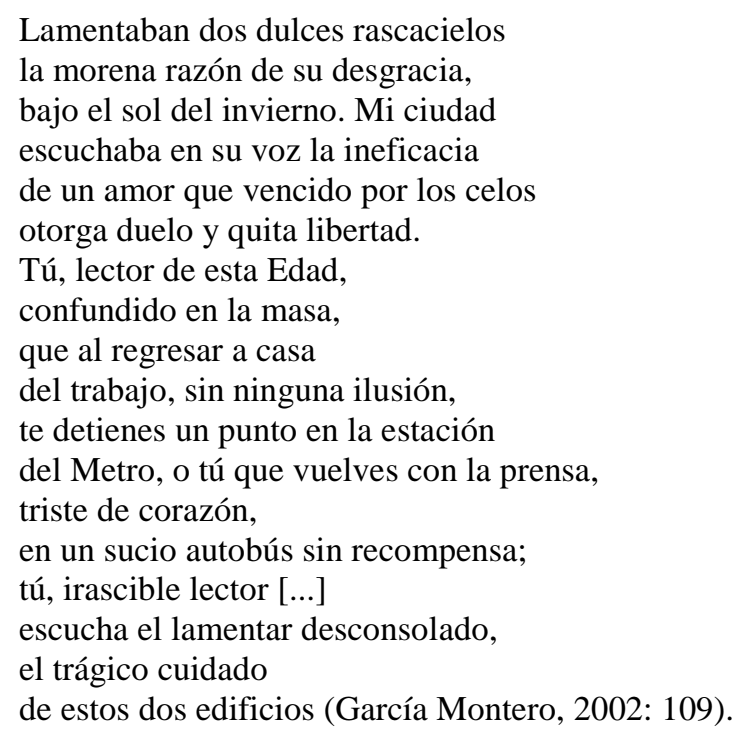

El singular realismo reivindicado por García Montero defiende la opinión contraria de la poesía social, instalándose en una especie de micro-historia constantemente nutrida por micro-relatos, episodios, estampas de la vida cotidiana. En la alianza estrecha entre vida privada y vida pública es donde el autor configura una lectura histórica de los destinos humanos: encuentros y separaciones, citas, soledades, paseos, viajes. Este cronotopo se articula a menudo a partir de aventuras sentimentales o amorosas, inscritas en una duración más o menos larga. Tal como esta pareja que cruza los tiempos difíciles de la posguerra; la fecha del encuentro está explicitada en el título: «Para ponernos nombre (1941)»: un antiguo soldado vencido y una cantante de cabaret viven sus amores como una compensación ante la derrota de sus destinos colectivos:

\footnotetext{
Fue quizá que los tiempos sólo hacían posible para un viejo soldado de todas las derrotas matar la soledad entre los brazos de una joven cantante de revista. [...]

Sólo un poco más tarde, cuando la brisa ciega del sesenta les hizo descubrir que envejecían, supieron que era hermoso atardecer unidos, abrazarse debajo de todas las banderas,
} 
Tropelías. Revista de Teoría de la Literatura y Literatura Comparada, 18 (2012) 61 Realista y sentimental: la experiencia de la cotidianidad y su relación con la polis

\author{
vivir la intimidad que la derrota impuso \\ no demasiado cerca del amor, \\ porque la vida \\ tan fiel como una hermosa melodía \\ acabó siempre por darles su razón (García Montero, 1991: 52-53).
}

La historia afectiva aquí se mezcla con las vicisitudes de un tiempo de miseria y opresión, que destruyeron para siempre las esperanzas de una juventud ansiosa de libertad.

Fuera del panegírico que pudo antiguamente caracterizar la poesía heroica o más recientemente la poesía épica de la guerra civil, la poesía ya no se atreve a cantar y contar la Historia colectiva, pero puede arrojar una luz parcial sobre episodios reveladores, fijando su atención no en los grandes personajes sino en las gentes ordinarias, como lo hizo Brecht. La biografía, aunque fuese fictiva -de cualquier personaje enfrentándose con sus esperas, sus ansias, sus frustraciones, sus éxitos y fracasos-, puede transformarse en un concentrado metonímico de los momentos más significativos vividos por una comunidad, o bien de los valores encarnados por sus parecidos. En el espacio urbano que sirve de sustrato a la existencia cotidiana observada por García Montero no todo obedece a una visión negativa. El personaje que capta desde el autobús la curiosidad de las mujeres por los escaparates que son emblema de la sociedad de consumo, refleja una imagen totalmente aceptada, incluso tranquilizadora, del mundo moderno, proveedor de un bienestar material que no es necesariamente desdeñable. Los anuncios publicitarios constituyen un incentivo, pero al mismo tiempo recuerdan que el acceso a los bienes de consumo resulta aún muy desigual. El texto "Mujeres" traduce la sensación de fallo entre una satisfacción imposible y una realidad que obliga a metas más modestas, que afloran a través de palabras amables intercambiadas a media voz:

\footnotetext{
Mañana de suburbio

y el autobús se acerca a la parada.[...]

Desde mi asiento veo a las mujeres, con los ojos de sueño y la ropa sin brillo, en busca de su horario de trabajo.

Suben y van dejando al descubierto, en los cristales de la marquesina, un anuncio de cuerpos escogidos y de ropa interior. Las muchachas nos miran a los ojos desde el reino perfecto de su fotografía, sin horarios, sin prisa, obscenas como un sueño bronceado.

Que tengas un buen día, que la suerte te busque
} 
en tu casa pequeña y ordenada,

que la vida te trate dignamente (García Montero, 1997: 158-159).

Jamás las tensiones entre individuos y colectividad habían sido llevadas al punto de incandescencia que alcanzan los poetas de la ciudad. El título con el que Fernando Beltrán compiló casi veinte años de producción poética es emblemático: El hombre de la calle. Este hombre, protagonista y narrador en una serie de estampas, no es sólo el hombre observado en su dimensión social, sino el individuo luchando con el peso del mundo, esa lenta instilación, muchas veces insidiosa, de los desórdenes que amenazan con arruinar los entusiasmos más fervorosos. Fernando Beltrán se sitúa en la estela de la "otra sentimentalidad", en la que la malla urbana (Beltrán, 2001: 16), según la expresión de Leopoldo Sánchez Torre, más que un mero telón de fondo, es el catalizador de relaciones antagónicas entre un sujeto partido y un mundo heterogéneo. Más aún, el análisis de lo cotidiano permite ver el mundo como una totalidad fragmentada desde la que están puestas en tela de juicio las relaciones jerárquicas o las relaciones con las instituciones: estado, escuela, cultura. La puesta en perspectiva de la cotidianidad organizada del espacio urbano se vuelve en los poetas de la ciudad un campo de investigación de los diversos mecanismos de alienación, de dominación, de rechazo, pero también de aceptación y de complicidad, que tienden a desplazar las fronteras de los espacios normalizados. La atenta mirada de Fernando Beltrán no se para sólo en las diferencias sociales entre los que acceden al bienestar y los que quedan marginados. La ciudad ostenta los signos de esta segregación con incursiones en el mundo de los excluidos, vividas como otras tantas amenazas o estigmas de una sociedad despiadada.

En la poesía de Beltrán, como en otros poetas de la ciudad, el espacio urbano queda interiorizado de manera ambivalente en torno a la noción de solidaridad, sea entendida en el sentido de contingencia, y en este caso el individuo no es más que el rehén del sistema sin que pueda modificarlo, sea entendida en el sentido de una "toma de partido" que descanse en un acto voluntario, y en este caso el individuo se proyecta en la experiencia colectiva, creyendo posible una transformación del sistema.

Evidentemente, el poeta no es ni antropólogo, ni sociólogo, pero la poesía de Beltrán, al apoyarse en la descripción de lo cotidiano, desarrolla una poesía figurativa que pasa revista al paradigma de los objetos familiares del universo urbano: transportes públicos, sirenas de ambulancias, anuncios publicitarios, carteles de espectáculos, etc. Todo esto no excluye una representación en el modo metafórico para significar el poder fagocitario de un modo de producción que devora a los individuos y las energías. ¿Dispone todavía el poeta del poder de resistir a las consecuencias de la masificación? Una mirada furtiva, un gesto apenas esbozado, un encuentro efímero con el otro (que 
Tropelías. Revista de Teoría de la Literatura y Literatura Comparada, 18 (2012) 63 Realista y sentimental: la experiencia de la cotidianidad y su relación con la polis

puede ser una mujer) condensan las huellas de una emoción que hace estallar los códigos establecidos. En Fernando Beltrán, el recurso a una retórica del oxímoron y la ausencia parcial de puntuación que establece ambigüedades entre los sintagmas tienden a mimetizar sensaciones complejas, tanto corrosivas como tranquilizadoras. En los versos de "Transbordos", el anónimo cruzarse con mujeres jóvenes en la muchedumbre, esperando el metro, es la oportunidad de un roce cuya brevedad pone de manifiesto la necesidad de reconstruir la relación social:

\author{
Me pregunto a menudo si realmente \\ ignoro a esas muchachas, \\ las que cruzan sin más como si fuera \\ el horario el culpable [...] \\ al comienzo cuando viajas \\ descendiendo a la cima \\ de tropezar con ellas, \\ ascendiendo hasta el pozo \\ de unos labios castaños \\ mirando al otro lado, \\ teléfonos fugaces y dos ojos mendigos \\ tocando su tristeza \\ en este acordeón de las mañanas \\ compartiéndolo todo [...] (Beltrán, 2001: 93-94).
}

\title{
2. Cotidianidad en el espacio urbano: Riechmann y Wolfe
}

La intención de claridad que acompaña la práctica de los poetas realistas de los años 80 está en los antípodas de la revolución mallarmeana. Hablamos de poesía figurativa cuando ésta designa los objetos constitutivos del mundo con un referente inmediatamente identificable. Pero quien suscribe semejante definición, ¿no será víctima de un "realismo ingenuo"?

Vimos anteriormente que el efecto cumulativo podía mimetizar la realidad, pero no le asigna por lo tanto un significado. Si con poetas como Jorge Riechmann o Roger Wolfe la expresividad huye del recurso a la metáfora, otras técnicas permitirán dar cuenta de la diversidad de lo real y de las dificultades para someterla a una lectura puramente ideológica. Eso explica la elección frecuente de la postura irónica del distanciamiento (del cual Ángel González fue sin duda un brillante exponente en los años 60, y los poetas de la urbe le deben mucho), y explica la aparición de un hojaldre de registros idiomáticos en la organización del texto, inducidos por los criterios de una estética kitsch. Los poetas habrán encontrado en esta fórmula una manera de objetivizar las contradicciones, mientras las prácticas políticas encuentran escapatorias en lo "políticamente correcto" que denuncia con sarcasmo Jorge Riechmann, haciendo la glosa de acontecimientos o hechos indecentes leídos en la prensa más seria. Por poner un ejemplo, Riechmann comenta la violación de la que fue víctima un partidario del 
boicoteo de los productos de la cadena comercial de la que Silvio Berlusconi es propietario:

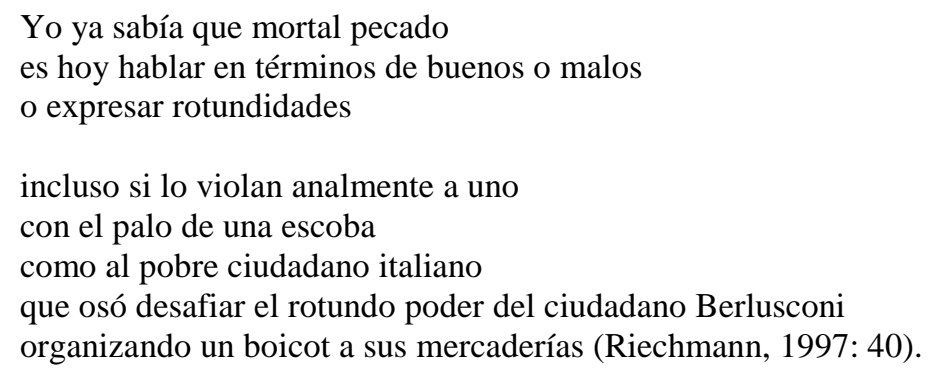

Lo "políticamente correcto" está asimilado con un nuevo error político, con una renuncia moral que afecta a todos los partidos de gobierno. Al final, con textos radicalmente provocativos, el poeta pone de manifiesto la situación trágica del militante ante las conductas estereotipadas que no logran "cambiar el mundo". Bajo una forma alegórica, Riechmann examina los imperativos morales que se imponen al militante y observa con desolación que su acción no modificó en nada el desorden del mundo. El hundimiento de las últimas utopías llevó al desencanto. Pero lo que cabe leer en filigrana en este discurso es un nuevo reparto de los imperativos morales desde la esfera privada. En esa dirección es hacia donde hay que buscar el reencanto de la acción política. En el poemario arriba citado, Riechmann plantea la cuestión de las finalidades de una acción política que tomaría en cuenta los intereses comunes privados :

He comenzado a organizar una selva para el traspapelamiento de deberes.

Siempre en el mismo libro, el autor repele las coartadas y vuelve a repartir los papeles, asignando a la poesía una función de despertar, pero no de sustitución; porque eso sería fomentar una falsa buena conciencia. En "Estado de la cuestión, 1996", escribe:

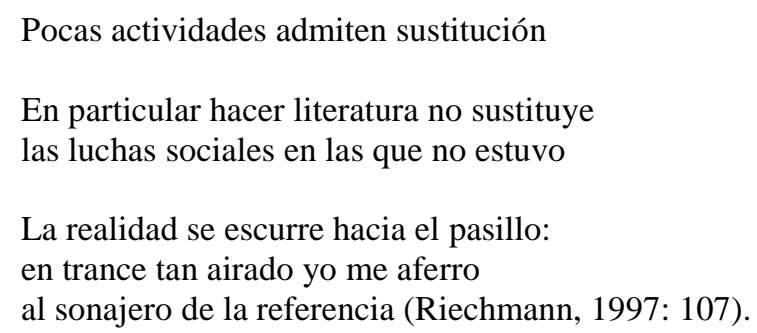

La transitividad está al servicio de un discurso que vuelve a colocar en el centro de sus preocupaciones el referente extratextual. De ahí el uso frecuente en la poesía riechmanniana de una retórica del vaciamiento que hace retroceder el texto hacia los 
ladillos jugando con los epígrafes, las notas infrapaginales o las alusiones a personajes políticos del pasado o del presente, técnicas que manifiestan las implicaciones factuales del "poema", o quizá del "anti-poema". Esta radicalidad nos lleva a los confines del poema, al caso límite en el que el texto entero está sacado de un artículo de prensa, debidamente mondado y sometido al ritmo sintagmático que lo transfigura. Así, el texto encuentra una nueva inversión enunciativa y semántica, sin ambigüedad, ya que informaciones paratextuales precisan que se trata de textos recreados ${ }^{2}$.

El peso del referente extratextual es tal que acaba por zarandear nuestros hábitos de lectura. El lector puede preguntarse si está aún en presencia de un texto poético. La poética realista practica aquí un trabajo de deconstrucción que pone en tela de juicio el valor de las informaciones a partir de las cuales el lector ciudadano se forja una opinión. El título mismo del poemario de Jorge Riechmann, El día que dejé de leer El Pais, deja suponer un gesto de rechazo ante la prensa dominante que tiende a ocupar el terreno libre dejado por la desaparición de los discursos de legitimación. En contra de esa ideología omnipresente de los medios se alzan Riechmann y ciertos colectivos que ven en la poesía -o, más bien, en una postura anti-poética, ya que está toda ella orientada hacia lo real- un modo de trastornar el discurso: de ahí el recurso a la ironía, el escarnio, el disparate. Todo pasa como si en la búsqueda de lo real, los autores recordaran la lección de Alfred Jarry, que veía en el jaleo humorístico la única manera de oponerse a los discursos positivistas, por esencia provisionales. Hay un texto de Riechmann que sintetiza a la vez su pensamiento y su práctica poética, y que es tanto más esclarecedor cuanto que glosa bajo la forma de paradiástole ${ }^{3}$ el emblema de la poesía social, forjado por Gabriel Celaya. Ese poema lleva por título "Tráfico de armas":

\author{
¿La poesía un arma \\ de futuro cargada? \\ A lo mejor gastó \\ mucha pólvora en salvas. \\ A lo mejor el tiro \\ salió por la culata. \\ Acaso, nadie supo \\ con tino dispararla. \\ Quizá estaba cargada \\ con pólvora mojada. \\ Acaso al cazador \\ su presa lo acosaba. \\ Quizá sólo la risa \\ puede rasgar la máscara, \\ puede quebrar las armas.
}

\footnotetext{
${ }^{2}$ Véase en El día que dejé de leer El País "El sueño del trabajo estable" (pp. 13-15), "Bienes y sevicias" (p. 50), "Ofrécese Súperlópez, 1996” (pp. 60-61).

${ }^{3}$ La paradiástole es una figura lógico-discursiva que articula una o varias secuencias de enunciados en un sistema de matización o distinciones precisas, generalmente apoyado en los paralelismos de la frase.
} 
El razonamiento de Riechmann consiste en deconstruir la metáfora inicial, jugando sobre varias frases hechas que tienen como punto común el uso de un arma de fuego, o mejor las malas jugadas que le pueden propinar al usuario. La inversión de la imagen es un procedimiento propio de la carnavalización. Este encadenamiento del significado que no se fija en ningún enunciado considerado en su secuencia aparentemente unitaria, se manifiesta más bien a través de su motilidad. En este caso, el rasgo de humor apunta la huida de lo real ante el flujo de los signos. La fórmula cerrada de la frase hecha es sobrepasada por la disposición serial de las fórmulas siguientes hasta el momento en que el final se cierra sobre sí mismo para dejar ver la imposibilidad de circundar lo real. Por lo menos habremos sentido en el tiempo breve de un fulgor que la poesía mantiene el deseo de religar las cosas.

Esto nos trae a definir lo cotidiano: todo cuanto ocurre día tras día y acaba por fundirse en una totalidad permanente. La vida cotidiana se desprende de un conjunto de interacciones subjetivas en un ir y venir constante entre el sujeto y el mundo. Sin embargo esta cotidianeidad es susceptible de lecturas diversas según la cultura, la edad, el género, la etnia, el nivel de vida. A mi modo de ver, los poetas realistas han encontrado en su trato con los objetos de la cotidianeidad una especie de pedagogía de la realidad. Son realistas porque adoptan y defienden actitudes que están en los antípodas de la búsqueda del ideal -trátese de experiencia mística o del refugio en la alucinación estética-; su manera de leer el mundo tiene por finalidad hacer sentir la alteridad rugosa del mundo que constituye la realidad, lo que nos permite decir que al mismo tiempo son "sentimentales". El principio de realidad está inscrito en el interior mismo del lenguaje, como da a entender Christian Prigent en un artículo reciente, "No se hace poesía sin romper huevos":

El mundo está doliente desde dentro del idioma, y habitarlo "poéticamente" quiere decir formalizar este estado latente irremediable -en las formas ("música verbal", "ritmos", "procedimientos calculados", etc.)- que no pueden de ningún modo escapar de la negatividad que las construye como formas. El objeto del poema (tanto lo que lo genera como lo que éste apunta) es este suspense, este estado latente, esta dolencia (Prigent, 2004: $57)^{4}$

Esta espera que la poesía intenta colmar pero que no puede expresar de manera positiva, está verbalizada como un esfuerzo que se agota creando presencia. Semejante idea no nos parece tan alejada del concepto de "realismo de investigación" propuesto por Jorge Riechmann:

Propugno un realismo de indagación, un realismo experimental, capaz de abrir senderos en el vasto continente de la realidad y capaz también de poner en cuestión sus propios procedimientos. El poeta no escribe sabiendo de antemano lo que va a encontrar.

\footnotetext{
${ }^{4}$ La traducción es nuestra.
} 
En poesía el realismo no tiene que ver con la representación. Es creación de presencia y no evocación de la misma. Un buen poema no es una fotografía sino una fuente de luz (Riechmann, $1998: 133)^{5}$

La atención a lo cotidiano en los nuevos poetas realistas tiene algo de paradójico: lo que el lector suele tomar por lo real (el espectáculo del mundo, la vida puesta en imágenes, lo vivido historicizado) está vaciado de su sentido por haberse desligado de toda identidad verificable. Ahora bien, la poesía no puede hacer presente como real más que las cosas a las que da corporeidad; es como un "hueco" que hace oír algo ausente. ¿Significará esto que el realismo en poesía da con la misma aporía que la búsqueda mallarmeana? No hay palabra bastante fuerte o suficientemente justa para expresar nuestra relación con el mundo al margen de una asignación permanente a lo simbólico. Esta es la tarea cotidiana del poeta: hacernos presente, como en hueco, lo que le lleva a escribir. Es bajo la especie de una poética realista como nos cumple leer el poema de Jorge Riechmann, composición breve en la que el autor da a entender que con la presión de lo cotidiano la poesía busca lo imposible:

\author{
DE CÓMO LA ATROCIDAD DE LOS HECHOS NECESARIAMENTE SE \\ VENGA EN EL HACEDOR \\ Voz devorada hacia adentro, \\ cáncer discreto. \\ Frutos. Luces. Movimientos. \\ Amar. Afeitarse. Hacer la compra. El cuerpo. \\ De un día para otro \\ -también en los bastiones de lo elemental- \\ lo indecible gana terreno (Riechmann, 1989: 64).
}

Así se entiende, desde una línea que acentúa la presencia de un referente realista, por qué un poeta como Roger Wolfe desarrolla una antiestética o una estética de lo feo, como quiera llamársele. La crítica es unánime al reconocer el carácter provocativo de la poesía wolfeana, en la que ha visto una influencia directa del realismo sucio norteamericano. Aunque el poeta reconoce su interés por Raymond Carver, rechaza tal etiquetaje. La verdad es que existe una tremenda diferencia entre sus declaraciones y su poesía, que encarna con creces una forma de realismo posmoderno culminante en la adopción de una total iconoclasia cultural, según expresión de Luis Bagué (2006: 271). De ahí una línea antiestética que es expresión de la inutilidad de la poesía o de la vacuidad del arte como leitmotiv de la producción wolfeana, ampliamente marcada por una reflexión metapoética. Las más de las veces, la crítica interpretó la indiferencia

\footnotetext{
${ }^{5}$ El texto se titula "Por un realismo de indagación (Homenaje a Joan Brossa)". Sobre las relaciones entre realismo y compromiso en los actuales poetas de lo cotidiano, véase el muy valioso artículo de Leopoldo Sánchez Torre "De lo real y sus retóricas” (Sánchez Torre, 2002).
} 
activa y el desencanto del poeta como un gesto de rebeldía ante las normas vigentes y la mediocridad de la sociedad de consumo. Comparte Wolfe con las poéticas neo-realistas temas idénticos, interesándose particularmente por los marginados para recabar los aspectos más degradados de la sociedad actual, asolada por los efectos demoledores de un capitalismo desbocado: droga, prostitución, mendicidad, marasmo moral que afecta a una juventud sumida en la desesperanza y el nihilismo, sin tabla de salvación. Frente a la marginación galopante, generada por la llamada "sociedad del bienestar", ya no existe la respuesta colectiva de las ideologías progresistas, de modo que el autor levanta su protesta desde un yo egotista, recluido sobre sí mismo y avasallado por el tedio, como da a entender el poema "Cinco años de cama". Amparado tras el muro del yo, el poeta examina sin meterse en complicaciones intelectuales los efectos aniquiladores procedentes de su entorno urbano, que lo llevan a una situación en la que experimenta lo absurdo de la existencia, como el Roquentin de La Nausée. «Realmente / no sé lo que me pasa. / No es asco. / No es hastío. / No es abulia. / No es cansancio. / No es indiferencia. / Es como si el mundo / se me hubiera / parado / encima» (Wolfe, 1998: 17).

Ahora bien, frente a esta actitud de casi postración, nacida de la contemplación de una sociedad socavada por vergonzosas desigualdades, aflora la protesta, la indignación, el rechazo de una propuesta anarquizante sin formulación ideológica clara, que a lo mejor podría justificar una lectura en clave cívica, pero que resulta muy distinta en su aspecto estético de lo que fue el realismo social de los años 50. Más aún, el propio Wolfe quiso reaccionar contra la corriente actual de la "poesía entrometida", porque ésta arrastraba pruritos reivindicativos a los que no quiere someterse. Aunque el poeta comparte con Fernando Beltrán, Jorge Riechmann y Antonio Orihuela el mismo punto de vista crítico sobre la sociedad capitalista, y acaba por adoptar la misma radicalidad antiestética, Wolfe nunca quiso que sus textos fuesen incorporados al colectivo onubense "Radicales, feroces y heterodoxos".

Sin embargo, sería muy difícil mantener que no exista una forma de compromiso en la poesía wolfeana. Lo que le diferencia de la concepción sartreana reside en su negativa a ceñir la obra a imperativos colectivos, ciertamente; pero menoscabaríamos esta aduciendo que el individualismo y la desconfianza de Wolfe ante los "enrolamientos" conduzcan su poética a formas en algún modo oblicuas del compromiso, las adoptadas desde posturas testimoniales frías, distantes y escépticas, desilusionadas ante las ideologías que propugnan la liberación o una reacción ante las desgracias del mundo. Al respecto, acaso la crítica no haya insistido suficientemente en su sentido político del humor y en la particular comicidad de los poemas wolfeanos. Cultiva el poeta el distanciamiento divertido que juega con el autodesprecio, lo grotesco 
-hasta el cinismo a veces- para denunciar y repeler con gestos procaces las violencias del mundo. De ahí la parodia de los discursos oficiales, los pastiches de jergas para desviar las retóricas de la alienación mediático-mercantil, empresarial, administrativa. En cierta medida, el poema "Las autoridades literarias advierten: ser feliz perjudica seriamente la salud" reúne gran parte de estos procedimientos:

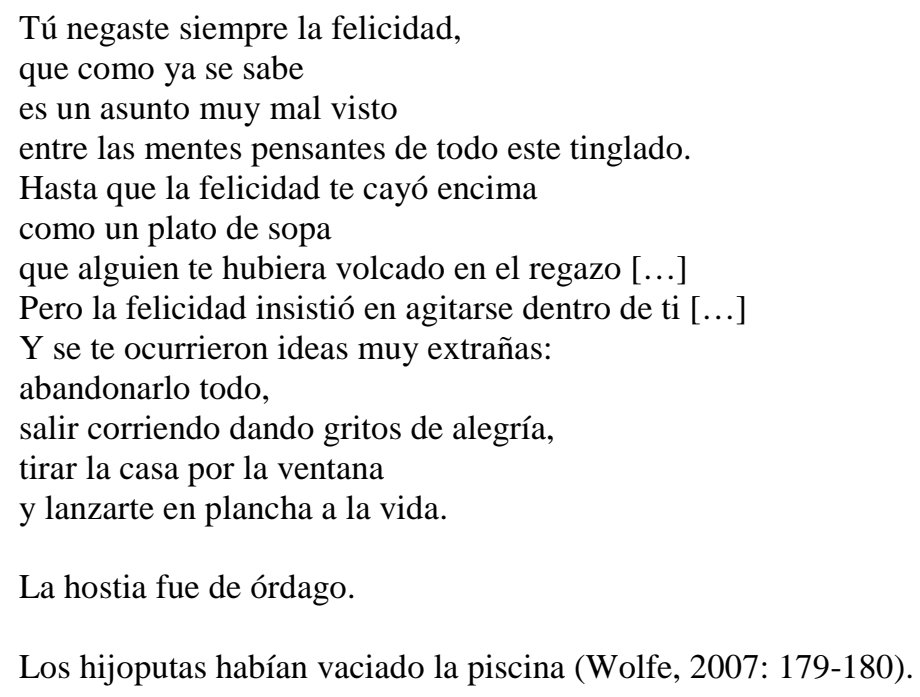

El interés de este poema es que matiza en cierta medida el nihilismo que suele ostentar Wolfe ante el futuro. Desviando los avisos de un paquete de cigarrillos avanza la idea de que la felicidad es un reclamo peligroso. El personaje poemático muestra su desconfianza ante lo que pudiera procurarle felicidad. Si ésta llega será por pura casualidad, pero el despertar es cruel. Todo queda entre alusiones, sin referencias concretas en el texto, aunque otros poemas identifican claramente la felicidad con los ocios triviales de la cultura de masas (deportes, telenovelas, vídeos, ir de copas). Luego, nada de meditación, apenas un cierre digno del lenguaje de un tebeo, un salir por peteneras: «La hostia fue de órdago. / Los hijoputas habían vaciado la piscina». Sin embargo, este final aparentemente absurdo y cómico es una señal para advertir sobre los peligros latentes que nos amenazan colectivamente. No tarda el poeta en denostar el sinsentido de una organización social que pierde de vista lo humano, contraproyecto evidente el suyo respecto del programa que se propuso el realismo social, que seguía confiando -y no desesperando- en la naturaleza humana como elemento de transformación de la sociedad. Desde luego, la protesta wolfeana tiene que buscar por otros derroteros su fuerza impactante, al desarticular los mecanismos arrolladores de la sociedad en la era de la masificación cultural, ahondando en lo trivial y superándolo con el humorismo.

Roger Wolfe no niega que el realismo sucio norteamericano lo haya influido, pero en una entrevista con Juan Luis Tapia aclara el concepto de la manera siguiente: «Lo de 
sucio, sería porque se trataba de un realismo manchado por la vida, pero no pretendía ser una cosa escatológica, sino historias de todos los días sobre problemas domésticos y cotidianos» (Iravedra, 2010: 215). Esta manera de enfocar el realismo nos parece plenamente ilustrado en las estrofas que citamos a continuación:

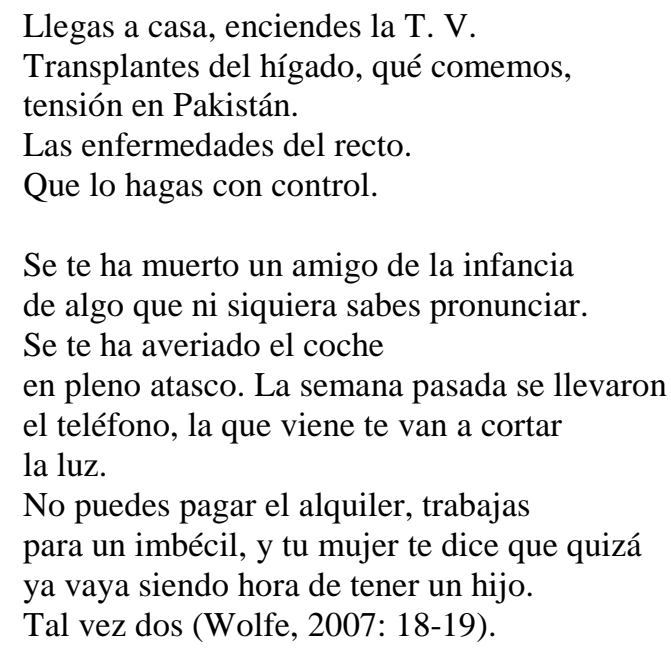

En esta manera de acercarse a la realidad, Wolfe tan sólo destaca, acumulándolos a un ritmo vertiginoso, trechos de representación ${ }^{6}$. De ahí la impresión, mediante el uso frecuente de la parataxis, de una superposición de estampas, o de escombros arrancados del fluir de la vida. A partir de una atenta observación de la sociedad, el poeta saca muestras de lo repetitivo, lo fosilizado, lo estereotipado de todo lo que forma la cotidianeidad, para enseñar a sus lectores lo que se oculta tras la pantalla de los días. La inventiva cuestionadora de Wolfe consiste en seccionar el flujo de las palabras socializadas para que nuestra mirada cale más hondo en el envés de las apariencias. Este modo de pensar no está carente de significación política.

Cabe insistir en el método wolfeano, que bien podríamos calificar de poesía de proximidad $^{7}$, por su manera de desarmar el tinglado de nuestra cotidianeidad según un fraseo cumulativo que mimetiza una huida hacia adelante, desde cierto prosaísmo que tiene inevitables desaciertos junto a indiscutibles hallazgos. Sea lo que sea, el sistema estriba en cierta concepción de la fragmentación fraseológica. Encontramos bajo la pluma de R. Wolfe destellos de metafísica bufa: «El hombre /. Es el único ser del

\footnotetext{
${ }^{6}$ Aunque no exista influencia entre ambos poetas, merece la pena cotejar la cita anterior con el caso de Charles Pennequin en Francia por su evidente parentesco con la poesía wolfeana. Veamos tan solo un ejemplo tomado de su libro Moins ça va, plus ça vient (Amiens, Le jardin ouvrier, 1999): «La télé mène une vie de con / la mienne surtout. // Ma vie dedans la sienne / de con. // Elle ma mené la vie dure / une vie de con tout l'été / je me sens maintenant tout autrement / et la télé ne mène maintenant à rien / l'été est passé / ma vie ne tient qu'à un fil / la vie de con continue».

${ }^{7}$ Debo la expresión a mi amigo Lucien Ghariani que hizo una magnífica presentación de la poesía de Roger Wolfe en el seminario de poesía de Paris IV (PIAL) el 16 de mayo de 2011.
} 
Tropelías. Revista de Teoría de la Literatura y Literatura Comparada, 18 (2012) 71 Realista y sentimental: la experiencia de la cotidianidad y su relación con la polis

universo / que necesita a Dios. / La naturaleza no necesita a Dios. / Mi perro no necesita a Dios»; impulsos aforísticos: «LA FAMILIA. De una conspiración de sangre / qué otra cosa cabía esperar»; briznas de un dietario introspectivo: «He aprendido / que tanto a una cosa como otra: / llamadas, recados, tareas o poemas»; arranques de cascarrabias y refunfuños de misántropo: «El que pueda pedir, que pida. Y el que no valga / a poner ladrillos. Y que se joda»; sentencias de tertulia: «No hay nada nuevo bajo el sol»; trechos de plática de familia: «Siéntate / a la mesa. / Bebe / un vaso / de agua. Saborea / cada trago»; secuencias de comentarios radiofónicos o televisivos: «Transplantes de hígado, qué comemos, / tensión en Pakistán. / Las enfermedades del recto». Todos esos rasgos estilísticos se acumulan como segmentos de "poesía cruda" hasta su coagulación en un conjunto coherente que cobra espesura con los comentarios sarcásticos del autor. Hay algo de invectiva en la andadura del poema wolfeano, entre el grafitti y el action writing. El sentido anida en el hueco de una resistencia negativa. Reside en este modo de mantener a distancia el sentido que suele fijar la prosa ordinaria hasta enquistarlo. Wolfe acaba por crear un ritmo y un lenguaje que le permite rasgar la superficie de la designación, fuera de los convencionalismos estéticamente establecidos, y lo hace con una intencionalidad fundamentalmente humorística, propia de la posmodernidad.

El filósofo Gilles Lipovetsky demostró en L'ère du vide que después del 68 nuestra época había entrado en la era de la sociedad humorística, opuesta a la gravedad y la seriedad de los comportamientos derivados del racionalismo ilustrado. Acelerada por el hundimiento de las ideologías, la cultura como explicitación del mundo ha cedido mucho terreno para dejar sitio a «la falta de creencia posmoderna y el nihilismo». El humor y el autodesprecio es lo que amalgama a los creadores que no quieren ilusionarse ni ilusionar a los demás. Desarrollan un humor de cariz desengañado. Lipovetsky ve en esta postura un rasgo definitorio del humor posmoderno, presente en muchas producciones artísticas (Lipovetsky 1993: 194-215). Puede decirse que la poesía wolfeana es ilustrativa de esta veta desmitificadora de la labor del artista que se emancipa de sus fundamentos sagrados. Sobre la base de una glosa a un conocidísimo poema de Quevedo, y en la encrucijada de una "poética del silencio", Wolfe opta por un minimalismo elocuente, que es como una especie de componenda entre la poesía figurativa y el distanciamiento moderno beckettiano, que permite el humor underground:

\author{
Este tipo dijo \\ con palabras elogiosas \\ que en el fondo \\ le agradezco:$$
\text { “...he aquí el milagro }
$$$$
\text { de una lírica }
$$ \\ que se construye \\ en el vacío...";
}




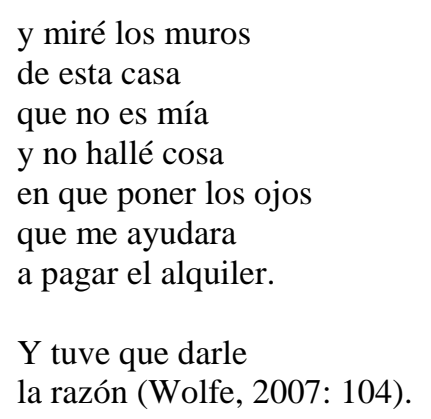

En su manera de descifrar todos los niveles de la cotidianidad, Wolfe propone un contradiscurso a la dramatización mantenida por los agentes mediáticos: sobre el ambiente de crisis, la inseguridad urbana y planetaria, las catástrofes y corrupciones, los fenómenos de marginación galopante. Desde luego, el contradiscurso no está para ofrecer soluciones sino para regentar un mundo poco satisfactorio, según lo que sabemos de él. La poética wolfeana no se limita a cultivar el prosaísmo para facilitar la comunicación sino que pretende con una labor de aflojamiento de los signos quitarles el lastre de la gravedad. El código humorístico que sustenta aquí el discurso pone las bases de una complicidad con el lector y aparece como un vector posible para la construcción de un ethos democrático. La no adhesión a una doctrina política identificable no significa, al fin y al cabo, que la poesía esté carente de función social. El trabajo con el lenguaje, tal como lo realiza Roger Wolfe, tiene de por sí una significación social.

\section{Referencias bibliográficas}

BAgUÉ QUíleZ, L. (2006): Poesía en pie de paz. Modos del compromiso hacia el tercer milenio. Valencia, Pre-textos.

BELTRÁN, F. (2001): El hombre de la calle. Granada, Maillot Amarillo.

GARCÍA MONTERO, L. (1993): Confesiones poéticas. Granada, Diputación Provincial de Granada.

- (1997): Casi cien poemas. Madrid, Hiperión. (2002): Poesía urbana. Sevilla, Renacimiento.

GARCÍA-POSADA, M. (1996): Poesía española. La nueva poesía (1975-1992). Barcelona, Crítica, vol. 10.

IRAVEDRA, A. (2010): El compromiso después del compromiso. Poesía, democracia y globalización (poéticas 1980-2005). Madrid, UNED.

LIPOVETSKY, G. (1983): L'ère du vide. Essai sur l'individualisme contemporain. París, Gallimard, 1993.

PRIGENT, C. (2004): L'incontenable. París, P. O. L.

RIECHMANN, J . (1989): Cuaderno de Berlín. Madrid, Hiperión.

— (1997): El día que dejé de leer El País. Madrid, Hiperión. 
Tropelías. Revista de Teoría de la Literatura y Literatura Comparada, 18 (2012) 73 Realista y sentimental: la experiencia de la cotidianidad y su relación con la polis

(1998): Canciones allende lo humano. Madrid, Hiperión.

RODRÍGUEZ, J. C. (1999): Dichos y escritos (Sobre la otra sentimentalidad y otros textos fechados de poética). Madrid, Hiperión.

SÁNCHEZ TORRE, L. (2002): «De lo real y sus retóricas», Ínsula, 671-672, pp. 49-53.

VILLENA, L. A. de, ant. (1992) : Fin de siglo. El sesgo clásico en la última poesía española. Madrid, Visor.

WOLFE, R. (1998): Cinco años de cama. Zaragoza, Prames. (2007): Días sin pan (Antología). Sevilla, Renacimiento. 